\title{
Selection of Early Bulking Performance Among Pro Vitamin A Cassava Genotypes Based on Selective Indices of Fresh Storage Root Yield and Harvest Index
}

\author{
Olusegun David Badewa ${ }^{1,2, *}$, Andrew Gana Saba ${ }^{2}$, Eli Kolo Tsado², Kehinde Dele Tolorunse ${ }^{2}$ \\ ${ }^{1}$ International Institute of Tropical Agriculture, Ibadan, Nigeria \\ ${ }^{2}$ Department of Crop Production, Federal University of Technology, Minna, Nigeria
}

Email address:

s.badewa@cgiar.org (O. D. Badewa), andrewganasaba@yahoo.com (A. G. Saba), ektsado@yahoo.co.uk (E. K. Tsado), kehinde.tolorunse $a$ futminna.edu.ng (K. D. Tolorunse)

${ }^{*}$ Corresponding author

\section{To cite this article:}

Olusegun David Badewa, Andrew Gana Saba, Eli Kolo Tsado, Kehinde Dele Tolorunse. Selection of Early Bulking Performance Among Pro Vitamin a Cassava Genotypes Based on Selective Indices of Fresh Storage Root Yield and Harvest Index. International Journal of Genetics and Genomics. Vol. 8, No. 1, 2020, pp. 11-18. doi: 10.11648/j.ijgg.20200801.12

Received: December 2, 2019; Accepted: December 19, 2019; Published: January 4, 2020

\begin{abstract}
Cassava provides energy sources for millions of people particularly in Africa where it is being planted mostly by rural subsistent farmers. The storage roots are rich in carbohydrates but deficient in vitamin A and consumption of which leads to hidden hunger as a result of insufficient intake of vitamins. The most widely approach in biofortification is conventional breeding which involves selection of varieties that is high in micronutrients such as vitamins and at the same time high yielding. However, cassava varieties cultivated by farmers usually stay long on the farmers field in a bid to wait to attain reasonable yield thereby preventing the land to be used for other crop cultivation. Another big issue is the problem of cattle invasion and bush fires that usually occurs in some areas. This has therefore necessitated the need to provide farmers with early bulking cassava varieties with considerable yield attainment and consequently reducing the stay of the crop on farmers' field while also improving the nutritional status through biofortification. As a result of this development, the farmers would have harvested their crop before the usual invasion of animals on their farm. This study evaluated ten cassava genotypes ( 8 yellow genotypes and a check with 2 white cultivar) considering their harvest index and fresh storage root yield in order to select the highest performing genotypes and to determine the relationship between the two indices as a measure of performance in terms of yield. The first four genotype that had high Harvest Index was identified and these traits was also correlated with yield. The study revealed that IKN 120036 and IBA141092 were the highest performing genotypes in terms of harvest index and fresh storage root yield.
\end{abstract}

Keywords: Root Yield, Early Bulking, Harvest Index

\section{Introduction}

Cassava (Manihot esculenta Crantz) is a perennial shrub originated in the neotropics and belongs to the family Euphorbiceae. It can tolerate poor soils and harsh climatic conditions and its most important product is the starchy roots used as a source of caloric energy by millions of people, particularly in Sub-Saharan Africa $[1,2]$. Cassava is the fourth most important basic food after rice, wheat, and maize worldwide, but is the second most important food staple in terms of calories consumed in sub-Saharan Africa [3, 4].
No other continents depend on Cassava to feed as many people as does Africa, where over 500 million consume it daily [5]. The crop is called Africa's food insurance because it offers reliable yields even in the face of drought, low soil fertility, low intensity management, and also because of its resilience to face the effects of climate change [6]. Five countries namely, Nigeria, Brazil, Indonesia and Democratic Republic of Congo produced $60 \%$ of the world cassava production [7].

Its storage roots form the basic carbohydrate element of the diet and the leaves are eaten as a preferred green 
vegetable in many parts of Africa. Tuber flesh colour and good culinary quality are important traits for consumption of cassava as staple food. In most of the cultivated cassava, the tuber flesh is white or cream which contain negligible number of carotenoids [8]. Nutritionally, cassava tubers are rich in carbohydrates, but deficient in many proteins and essential micronutrients. Carotenes ( $\alpha$-carotene, $\beta$-carotene, lycopene) represent the most multifaceted group of pigments in nature, with colors varying from yellow to red, found in photosynthetic and non-photosynthetic tissues, such as roots, seeds and fruits. Provitamin A carotenoids (pVAC) including $\alpha$-carotene, $\beta$-carotene and $\beta$-cryptozanthine are precursors of vitamin A, a micronutrient essential for normal development and functioning of the human body. Once ingested, $\beta$ carotene is transformed in the liver into Vitamin A. Vitamin A is a micro-nutrient with functions related to vision, cell differentiation, growth development, reproduction and the immune system [9].

Vitamin A exists in natural products in many different forms: as preformed retinoids, stored in animal tissues and as provitamin A carotenoids (pVAC), which are synthesized as pigments by many plants and are found in different plant tissues [10]. Vitamin A deficiency (VAD) is a preventable tragedy that affects millions of people, particularly in subSaharan Africa [11].

Cassava contains high level of $\beta$-Carotene which is precursor of Vitamin A. and poor-quality diets characterized by high intakes of staple foods with low consumption of sources of bioavailable vitamins and minerals causes micronutrient malnutrition [12].

Cassava harvesting usually depends on the consumer as it is usually ready as soon as it has formed reasonable storage roots. The storage root yield, as preferred by the farmer, is usually from 6-7 months after planting [13]. Cassava has a relatively long, 9-month to 2-year growing season, and a remarkably high harvest index, that means the ratio of weight of economically useful parts to total biomass production [14].

Late harvesting is usually due to low yields of cultivated cassava. Late bulking cassava stays longer on the farm, predisposing it to bush fires and animal invasion, particularly during dry season. Late bulking cultivars occupy land for extended periods of time and consequently the land cannot be effectively utilized for other crops. This is the most important factor responsible for rejection and abandonment of cassava cultivars in African countries [15, 16]. Farmers usually cultivate local varieties with low yields whereas high yielding and early-bulking varieties could only guarantee higher yields when harvested at 12 months [17].

Cassava root formation depends on the photosynthetic abilities of the leaves (source) to make sugar (sucrose) to be transported to the sink (storage roots). The source ability to produce chemical energy needed for plant metabolism is dependent on plant's use of light energy and its ability to convert $\mathrm{CO}_{2}$ into carbohydrates for plant use. The transport and partitioning of sugars from the source to the sink plays an important role in crop productivity [18] and the transfer of sugar from the source to the sink is photosynthetic dependent. The systematic distribution of photosynthate is known as assimilate partitioning [19] and the total biomass produced by a crop results from the integral of photosynthetic assimilation over the growing season less all respiratory losses and it depends on the efficiencies with which the crop intercepts light and converts that into biomass over the course of the growing season [20,21].

Storage roots at an early stage needs supplies of sucrose for metabolic maintenance and for its development [22]. The number of storage roots and their mean weight are yield components that determine sink capacity [23]. The root requirements for sugar must be aggressive as this will determine the movement of assimilates from the chloroplast through the plasmodesmata in sympastic unloading of the phloem. Ability of the root to unload the sugars from the phloem determines sink strength and numbers of roots increases the sink strength [23]. However, differences exist in sink capacity among cassava genotypes [23-25].

The efficiency of storage root production is measured by Harvest Index (HI) and is usually determined by the ratio of storage root weight to the total plant weight. The dry matter accumulation depends upon photo assimilate availability and the sink capacity of storage parts. When assimilates enters through the post sieve element of the companion cell complexes into the sink, it could either be used as metabolic pathway where it could be stored as starch in the storage root or be stored in organelles such as amyloplast, protein bodies and vacuoles [26]. The distribution of dry matter to the roots can be measured by harvest index and can be used as a selection criterion for higher yield potential in Cassava. Harvest Index values of $0.49-0.77$ have been reported in cassava after 10-12 MAP. [27].

For this reason, the objective of this study was to evaluate the performance of cassava genotypes using harvest indices and fresh storage root yield and to examine the relationship between Harvest index and fresh storage root yield.

\section{Materials and Methods}

\subsection{Experimental Material}

Ten cassava genotypes sourced from IITA germplasm, namely IKN120036, IKN120016, IBA070593, IBA130896 and IBA141092, TMEB419, IBA090525, IBA090581, IBA130818, IBA980581 were used for this study. The genotypes are yellow fleshed-root cassava genotypes with two white checks and a provitamin A check. The genotypes were selected based on their carotenoid content. It has three checks, two white varieties (IBA980581, TMEB419) and a yellow genotype (IBA070593).

\subsection{Experimental Site}

The study was conducted at the International Institute of Tropical Agriculture (IITA) Trial Fields, ABU farms, Mokwa, Niger state. (Southern Guinea Savannah Zone with Global Positioning System (GPS) co-ordinates of $06.32812^{\circ} \mathrm{N}$, $005.63599^{\circ} \mathrm{E}$ and altitude of $212.7 \mathrm{~m}$ ) from 2018 to 2019 . 


\subsection{Treatments and Experimental Design}

The treatments were genotypes (IKN120036, IKN120016, IBA070593, IBA130896, IBA141092 TMEB419, IBA090525, IBA090581, IBA130818, IBA980581) and harvesting periods of $3^{\text {rd }}$ and $6^{\text {th }}$ Months After Planting (MAP) arranged in a randomized complete block design, with three replications. Treatment plots per block consist of six ridges of $4 \mathrm{~m}$ length and $1 \mathrm{~m}$ apart. The net plots contain 16 plant stands with $24 \mathrm{~m}^{2}$ treatment plot size while the total treatment plot per replicate was $120 \mathrm{~m}^{2}$ and gross replicated area was $420 \mathrm{~m}^{2}$. The genotypes were planted at a spacing of $1 \mathrm{x} 0.8 \mathrm{~m}$ in 3 replicates in 2018 .

\subsection{Cultural Practice}

\subsubsection{Land Preparation}

The land was mechanically prepared with tractor and cassava stakes was planted on ridges. The ridges in each treatment plots per block is $1 \mathrm{~m}$ apart and of $4 \mathrm{~m}$ length.

\subsubsection{Planting}

Cassava cuttings with same nodes number was cut at $2.5 \mathrm{~cm}$ length and planted on all the ridges, making the planting distance of $0.8 \mathrm{~m}$ inter row and $1 \mathrm{~m}$ intra row spacing with 36 plant population and at an orientation of angle $45^{\circ}$ and data was taken from each of the blocks on the net plot area only. The 36 cuttings/stakes of each genotype were planted on each of the ridged field per treatment plot which measured 6 $\mathrm{x} 4 \mathrm{~m}$. The net plot is $24 \mathrm{~m}^{2}$ with 16 plant stands while the experimental size area is $30 \mathrm{mx} 14 \mathrm{~m}\left(0.0420 \mathrm{~m}^{2}\right)$ which contain 540 plants stands. No fertilizer was applied and the field was kept free of weeds by regular hand using hoe weeding as from three (3) months after planting (MAP). Harvesting was manually done by using hand to pull out cassava from the soil at $3^{\text {rd }}$ and $6^{\text {th }}$ months After Planting (MAP).

\subsection{Data Collection}

Data were collected per plot basis. Each plot contained six rows of five plants per row. Harvesting was done at 3 and 6 MAP and growth and yield parameters were taken. Data were taken from the net plot at the two harvesting periods.

\section{Yield Parameters}

Root size: This was taken based on the groupings according to the girth, length and weight of the stems into 3 marketable sizes; small, medium and big with score of 3,5 and 7 respectively [28].

Fresh Storage Root Yield (FSRY): This was obtained by multiplying weight of known number (n) of bulked root weight by 10,000 and dividing it by the known number of bulked roots multiplied by 1,000 and express in tha ${ }^{-1}$.

Shoot weight (Shtwt): This was obtained by weighing the stalks during harvesting using spring balance (kilogramme).

Harvest Index (HI): This was obtained by dividing the weight of the roots at harvest by the sum of weight of roots and the above ground mass as described by Kawano. [29].

Dry Matter Content (DMC): The dry matter percentage in tubers will be determined by drying $20 \mathrm{~g}$ of fresh tuber slices/cubes or chopped pieces in an oven at $50{ }^{\circ} \mathrm{C}$ till a constant weight was obtained. From the weight of dried sample, percentage of dry matter will be calculated using $\mathrm{W}_{\mathrm{m}}-\mathrm{D}_{\mathrm{m}} / \mathrm{W}_{\mathrm{m}} \times 100$ and $\mathrm{DMC}$ will be calculated by subtracting percentage dry matter from 100 . where $\mathrm{W}_{\mathrm{m}}$ is the wet mass, $D_{m}$ is the dry mass.

\subsection{Data Analysis}

Data were analyzed using analysis of variance (ANOVA) with the generalized linear model procedure of SAS (version 9.3). Where the ANOVA test indicated significant differences, treatment means were separated using Fisher's protected least significant difference (LSD). Linear correlation coefficients were calculated among agronomic parameters to investigate their relationships using the proc corr procedure of SAS.

\section{Result and Discussion}

\subsection{Harvest Index}

Cassava storage roots reach $50-60 \%$ of the total dry matter around 4 months after planting [27]. The rate of accumulation depends on the genotypes and the growing conditions. The distribution of dry matter to the roots can be measured by harvest index and can be used as a selection criterion for higher yield potential in Cassava.

Table 1. Mean Value, Coefficient of variation, ranges and mean square of yield components traits at 3 and 6 MAP combined.

\begin{tabular}{lllllll}
\hline \multirow{2}{*}{ Character } & \multirow{2}{*}{ Mean } & CV & Min & Max & 3 MAP & 6 MAP \\
\hline DMC & 33.02 & 16.62 & 24.64 & 4.11 & $33.02^{\text {ns }}$ & $35.42^{\text {ns }}$ \\
FSRY & 2.14 & 21.03 & 0.98 & 3.61 & $2.14^{* *}$ & $2.09^{* *}$ \\
HI & 0.38 & 23.95 & 0.11 & 0.56 & $0.38^{* *}$ & $0.39 * * *$ \\
RTSZ & 3.13 & 9.52 & 3.00 & 4.33 & $3.13^{* *}$ & $4.67^{* *}$ \\
\hline
\end{tabular}

$* * *, * * *$ Significant at $0.05,0.01$ and 0.001 probability levels, respectively. $\mathrm{MAP}=$ Month After Planting, DMC $=$ Dry Matter Content, FSRY=Fresh Storage Root Yield, HI=Harvest Index, RTSZ= Root Size.

In this experiment, harvest Index was significant $(\mathrm{P}<0.01)$ at 3 Month After Planting (MAP) and very highly significant $(\mathrm{P}<0.001)$ at 6 MAP (Table 1). Harvest Index values of 0.49 0.77 have been reported in cassava after 10-12 MAP [27]. Genotype IBA141092 had the highest HI of 0.56 and 0.6 at $3 \mathrm{MAP}$ and $6 \mathrm{MAP}$ respectively while genotype IBA130818 had the least of 0.11 and 0.12 at $3 \mathrm{MAP}$ and $6 \mathrm{MAP}$ respectively (Table 2). This shows that genotype IBA141092 among all the studied genotype was able to partition dry matter to the storage root earlier. However, the partitioning reduces at 6 MAP and this could be genotype or environmental specific as environmental factors, biotic and abiotic conditions could affect sugar allocation to the roots [30]. Leaves efficiencies in intercepting light also affects dry matter partitioning in cassava [31].

Harvest Index (HI) represents the efficiency of storage root 
production and is usually determined by the ratio of storage root weight to the total plant weight. Dry matter accumulation in roots depends upon photo assimilate availability and the sink capacity of storage parts. The number of storage roots and their mean weight are yield components that determine sink capacity [27]. Large variability in harvest index (HI) exist between IBA980581 (Check) at 3 and 6 MAP with HI ranging from 0.38 to 0.46 and the $\mathrm{HI}$ at $3 \mathrm{MAP}$ was higher than the $6 \mathrm{MAP}$. Genotype IBA090581 and IBA130818 had the most relatively stable HI with 0.44 to 0.45 and 0.11 to 0.12 at 3 and 6 MAP respectively.

Table 2. Mean Performance of Genotypes at 3 and 6 MAP.

\begin{tabular}{lllllll}
\hline \multirow{2}{*}{ GENOTYPE } & \multicolumn{2}{l}{ 3 MAP } & & & \multicolumn{3}{c}{ 6 MAP } \\
\cline { 2 - 7 } & HI & FSRY & Rank & HI & FSRY & Rank \\
\hline IBA070593 (C) & 0.34 & 2.16 & 6 & 0.38 & 2.17 & 5 \\
IBA090525 & 0.52 & 2.00 & 5 & 0.49 & 1.89 & 7 \\
IBA090581 & 0.44 & 2.59 & 3 & 0.45 & 2.32 & 3 \\
IBA130818 & 0.11 & 0.98 & 10 & 0.12 & 0.89 & 10 \\
IBA130896 & 0.31 & 2.16 & 7 & 0.33 & 2.17 & 6 \\
IBA141092 & 0.66 & 2.63 & 2 & 0.60 & 2.65 & 2 \\
IBA980581 (C) & 0.46 & 2.29 & 4 & 0.38 & 2.28 & 4 \\
IKN120016 & 0.23 & 1.31 & 9 & 0.27 & 1.32 & 9 \\
IKN120036 & 0.54 & 3.61 & 1 & 0.53 & 3.47 & 1 \\
TME419 (C) & 0.34 & 1.72 & 8 & 0.38 & 1.71 & 8 \\
\hline
\end{tabular}

FSRY $=$ Fresh Storage Root Yield, HI $=$ Harvest Index, MAP $=$ Month After Planting. $\mathrm{C}=\mathrm{Check}$

\subsection{Root Yield}

Leaves begin to grow from 2 MAP to 3 MAP and it has been shown to have a positive correlation with root yield. This shows that tuberous root yield correlates with sugars produced in the leaves during photosynthesis. Fresh storage root yield was highly significant $(\mathrm{P}<0.01)$ at $3 \mathrm{MAP}$ and at 6 MAP (Table 3). Tuberous root yield has been reported to be positively correlated with the soluble sugars in the leaves [32]. This means the higher the soluble sugars in the leaves the higher the photosynthetic activities and thus higher partitioning to the roots. However, sucrose and glucose in the cassava leaves also regulates the gene coding for the protein responsible for photosynthesis activities and if photosynthesis thus increases, there will be increase in the amount of sucrose and glucose in the leaves and these are responsible for the down-regulation of genes responsible for photosynthesis except there is high sink demand and transport capacity to remove additional sugars produced from the leaves [33]. An increase in photosynthesis occurs as a result of increase in $\mathrm{CO}_{2}$ which leads to increase in sugar production. The increase in sugar production in the source (leaves) affect the source-sink balance of plants which leads to increase in production of more sugars in the source tissues than it can be effectively used by the sink tissues [34]. In other words, since increase in photosynthetic efficiencies increases yield as reported by Amanda et al [35]. This means that if photosynthesis increases and there is increases in sugars produced in the leaves, without higher sink demand, it will lead to reduction in photosynthetic efficiencies.

High and low yielding cassava cultivars differs in their bulking rate and the period at which they exhibit the maximum bulking rate [36]. Environmental conditions that limits storage root bulking will adversely affect late bulking genotypes due to differences in sink-source relationship at different stages in their phenology [37]. Early maturing genotypes exhibit maximum bulking rate during their early growth stages compared with late maturing genotypes and this depends on growth conditions particularly moisture content which may affect the choice of sink [38]. High yielding genotypes have a high bulking rate over a long period, while genotypes with low storage root yield have a low bulking rate for short duration or long duration [39-40].

Early bulking and high storage root yield are usually coselected, there is therefore huge need for developing early bulking cassava genotypes due to greater demands by farmers [41]. Unlike other crops where earliness could be measured by associated traits such as plant height, flowering timing, node of first fruiting branching, growth period etc. same do not applies to cassava $[39,41]$. Cassava has differential partitioning of dry matter into the above ground mass and roots [42]. In selection for high storage root yield, dry matter partitioning is important determinant and could be major criteria for selection in breeding program for Fresh Storage Root yield (FSRY) [43]. Distribution of carbohydrates to the different organs of cassava changes during growth cycle with the shoot being the major sink during the first 5 months and storage roots the major sink later [44].

From 6 MAP to 10 MAP, photo assimilates partition from the leaves is accelerated making the root bulking faster and highest rate of dry matter accumulation occurs at 10 MAP$12 \mathrm{MAP}$ because at this period leaves are no more growing and the roots get maximum dry matter partitioning [45] Since leaves are no more growing at this period, this is possible due to the storage root regulating the carbon status of plant during night and day and therefore influencing photosynthetic capacity [34].

Genotype IKN120036 was the highest in terms of FSRY at 3 months after planting (MAP) followed by IBA141092 while genotype IBA130818 had the lowest FSRY at the same month as shown in table 2. At 6 MAP, genotype IKN120036 still maintained the highest yield at 3 MAP followed by IBA141092 while genotype IBA130818 still had the lowest FSRY (Table 2).

Table 3. FSRY relationship with other yield traits.

\begin{tabular}{llll}
\hline \multirow{2}{*}{ Yield component } & FSRY & 3 MAP & \multirow{2}{*}{ 6MAP } \\
\cline { 2 - 3 } & Correlation Coeff. (R) & P-Value & \\
\hline Root Size & 0.41 & $0.0060^{* *}$ & $0.0066^{* *}$ \\
Harvest Index & 0.61 & $0.0018^{* *}$ & $<0.0001^{* * *}$ \\
Dry Matter Content & -0.3 & $\mathrm{~ns}$ & $\mathrm{~ns}$ \\
\hline
\end{tabular}

$*, * *, * * *$ Significant at $0.05,0.01$ and 0.001 probability levels, respectively. $\mathrm{MAP}=$ Month After Planting, $\mathrm{ns}=$ non-significant 


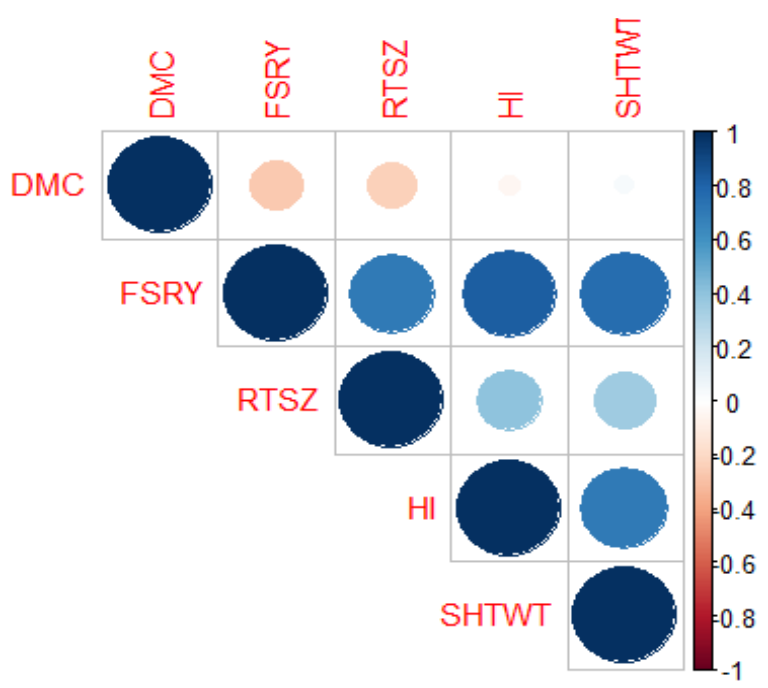

Figure 1. Pearson Correlation among root yield parameter. DMC $=$ Dry matter content, FSRY=Fresh storage root yield, RTSZ $=$ Root size, HI=Harvest index, SHTWT= Shoot weight.

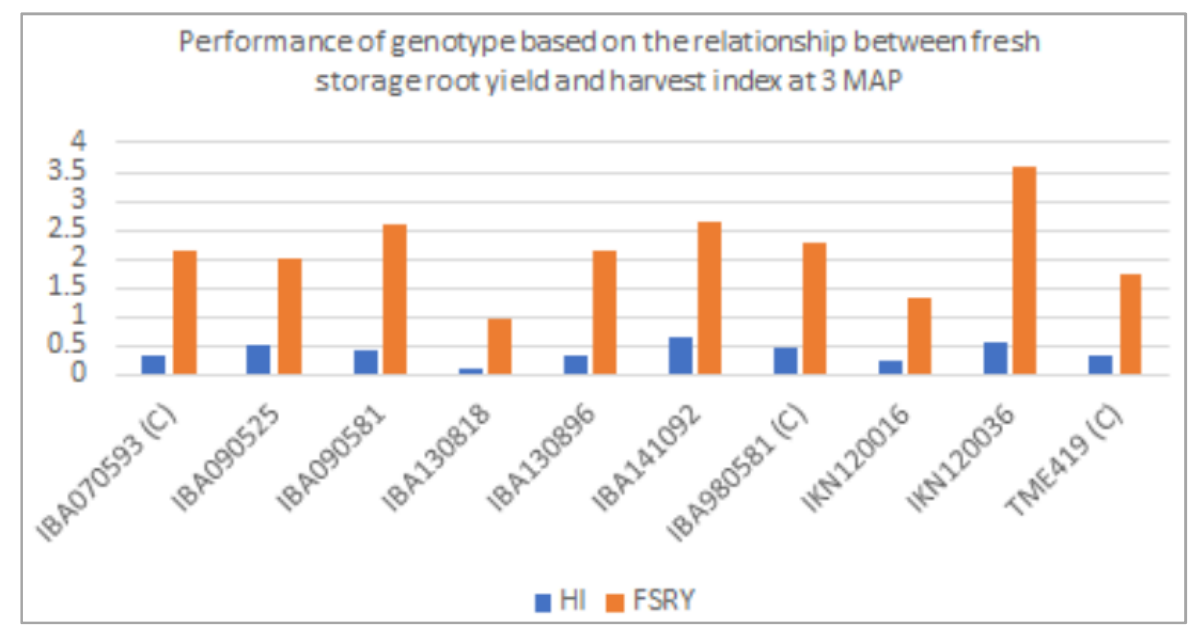

Figure 2. Cassava genotypes performance based on the indices of fresh storage root yield and harvest index at 3 months after planting.

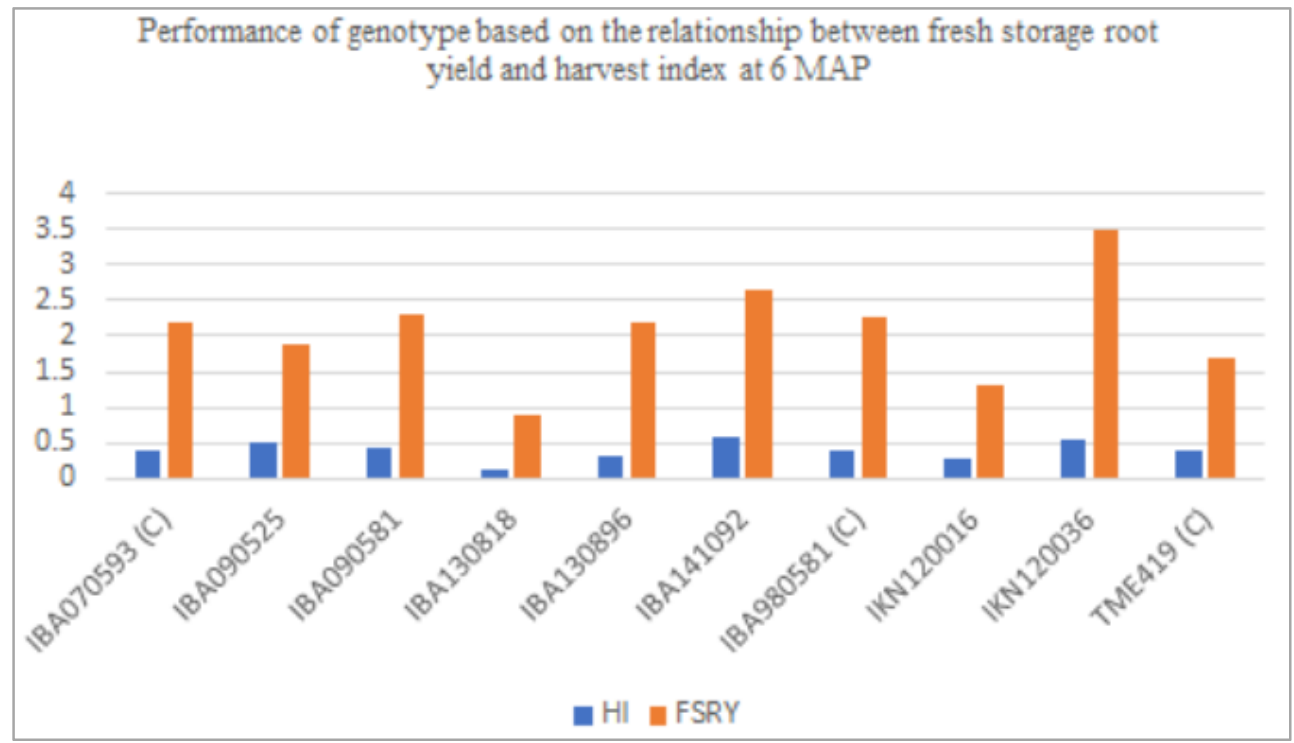

Figure 3. Performance of cassava genotypes based on the indices of fresh storage root yield and harvest index at 6 months after planting. 


\subsection{Root yield Parameter Relationship at 3 and 6 Month After Planting (MAP)}

Negative correlation between harvest index (HI) and shoot weight (Shtwt) (Figure 1) is an indication that at an early growth stage of cassava, dry matter accumulates more in the leaves than in the storage root. Similar result was reported by Silva et al [46]. However, Lessa et al [47] found no significant relationship between the two. Since HI measured the distribution of the dry matter and therefore measure the efficiency of storage root production, assimilates produced by the plant is still at the source and the utilization sink zone due to active growth of the plant [27]. Cassava is at active growth stage from 3-6 month after planting (MAP).

In vegetative plant, lower leaves are the principal supplier of photo assimilate to the root while the upper leaves are the principal supplier to the shoot apex while at the onset of the reproductive development, fruits and seeds becomes active sink for photo assimilates [26] Plant development especially for actively dividing cells such as the storage sink such as the roots depends on the relationship between the mechanism of photosynthesis and export of assimilates from the source to sink. Utilization of photo assimilates produced by the vegetative source can influence or regulate photosynthesis [48]. Sink activity can be represented by the product of number of actively growing rate and dry matter incorporation rate. However, photosynthesis has been reported to increase only when there is decrease in source to sink ratio [49]. For instance, the pattern of photosynthesis of leaves do not synchronize with assimilate demand of the source in cotton plant (Krieg, 1983). Photo assimilates partitioning from leaves to the storage roots starts at 6-10 MAP and there is highest rate of dry matter accumulation at this stage [50].

Dry matter content (DMC) negatively correlated with fresh storage root yield (FSRY). Since cassava active growth stage is between the period of 3 to 6 MAP, negative correlation between DMC and FSRY is expected because at this period, $\mathrm{DMC}$ is present in the leaves for active growth requirement. Therefore, no assimilates is distributed at the sink (storage root) at this time. The high sink strength is mediated by actively growing region [27]. However, Aina et al [51] found out that dry matter showed no significant correlation with fresh storage root yield after 12 MAP. Similar result was reported by Ojulong et al [52] and Kawano et al [29].

Negative correlation between DMC and $\mathrm{HI}$ is expected because of the negative correlation DMC had with FSRY in this study. All assimilates produced is to enhance the photosynthetic apparatus at this stage of growth (1-6 MAP) [27]. DMC partitioning starts from 6 MAP and above and the negative correlation could be as a result of DMC not yet partitioned at the storage root. Lessa et al [47] in their study found out that there was no relationship between $\mathrm{HI}$ and DMC in their study carried out over two crop cycles.

Positive correlation between root size (Rtsz) and DMC is expected because from $6 \mathrm{MAP}$, the leaves have attained maximum stage of growth [27]. From this moment, dry matter is being partitioned into the storage root yield. There is higher sink to source relationship at this stage because leaves growth stages have reached the peak. Higher DMC partitioning continues from this period. Negative correlation was discovered between FSRY and Shoot weight (Shtwt) and this is because dry matter is yet to be partitioned to the storage root yield. At this stage, shoot development is the major sink [35]. Tuberous root development starts c. 2 months after planting, before maximum investment in leaf biomass. Although tuberous roots are bulking throughout this period, shoot development is dominant and appears to have priority over root growth [53]. In other words, photo assimilates are not preferentially partitioned to tuberous roots until shoot growth nears completion, which usually occurs c. 6 months after planting [35]. This is evident in the negative correlation between the DMC and FSRY, it means at this stage, more assimilates is still being partitioned to the shoot at the expense of the root.

\subsection{Harvest Index and Fresh Storage Root Yield}

Harvest Index (HI) is used to measure the distribution of dry matter in plants. In case of cassava, it is a measure of the efficiency of root storage production. HI was positively correlated with Fresh Storage Root Yield (FSRY) and the two genotype that had higher HI corresponding to higher FSRY at 3 and 6 MAP are IKN120036 and IBA141092 (Figures 2 \& 3). Positive correlation between HI and FSRY has also been reported by Aina et al., [51] and Rodrigo de Souza [54]. Dry matter began to be distributed at a point when the leaves have attained its growth and photosynthetic peaks. Positive correlation in this study confirmed various studies that cassava crop starts dry matter partitioning from 6 MAP. The leaves production reduces henceforth and the dry matter partitioning increases. This could be due to the reduction in the use of photosynthate produced by the source (leaves) and due to efficient $\mathrm{CO}_{2}$ mechanism of cassava during the close of stomata in ensuring production of photosynthate thus, leading to increase in assimilates directed towards the storage roots. Jailson et al [55] have reported the relationship between $\mathrm{CO}_{2}$ effect and root storage during water stress.

The greatest range of HI values among genotype was observed for genotype IBA980581 (Check) having 0.46 and 0.38 at 3 and 6 MAP respectively while genotype IBA141092 had the highest HI at both 3 and 6 MAP and genotype IBA130818 had the least HI values at both 3 and 6 MAP. However, IBA 980581 (Check), IBA 090525, IBA 141092 and IKN 120036 partitioned assimilates to the storage root earlier than the rest of the genotypes having higher HI at 3 MAP than at 6 MAP and are among the top five performing genotypes on the basis of fresh storage root yield and harvest index.

\section{Conclusion}

Root yield is one of the cassava farmers' preference traits. Cassava root yield can be selected based on Harvest index 
and Fresh root yield. When these two traits are combined, this could help to predict the varieties with high yielding performance. This study showed that IKN 120036 and IBA141092 were the highest performing genotypes in terms of harvest index and fresh storage root yield due to the earlier partitioning of photo assimilates to the storage roots compared with the other cassava genotypes.

\section{Acknowledgements}

The authors would like to thank Professora Moemy Moraes of the Plant Physiology Department, Insitituto de ciencias Biologicas, Universidade Federal de Goas, Goainia, Brasil for her valuable input and feedback on the manuscript and to emeritus professor Nassar N. M. A. of the Departamento de Genética e Morfologia, Universidade de Brasília, Brasíl, DF.

\section{References}

[1] Stapleton G. (2012) Global starch market outlook and competing starch raw materials for starches by product segment and region. Cassava Starch World 2012. Centre for Management Technology (CMT), Phnom Penh.

[2] Norton R (2014). Global starch market outlook and feedstock economics. Cassava World. Africa 2014. Centre for Management Technology (CMT) Lusaka.

[3] Caccamisi D. S. (2010) Cassava: Global production and market trends. Chronica Horticulturae. 50 (2): 15-18.

[4] Tarawali G, Iyangbe C, Udensi U. E, Ilona P, Osun T, Okater C, and Asumugha G. N. (2012) Commercial scale adoption of improved cassava varieties: A baseline study to highlight constraints of large-scale cassava based agro-processing industries in Southern Nigeria. J. of Food Agr and Env. 10: 689-694.

[5] Tufan H. A. (2013). Next Generation Cassava Breeding Project. 2013. http://www.nextgencassava.org/about.html.

[6] Burns A, Gleadow R, Cliff J, Zacarias A and Cavagnaro T. (2010). Cassava: The drought, war, and famine crop in a changing world. Sustainability. 2: 3572-35607.

[7] FAOSTAT (2016). FAO Statistical Yearbook. Rome, Italy: Food and Agricultural Organization of the United Nations.

[8] Lovina I. Udoh, Adenubi Adesoye I. and Melaku Gedil (2017) Identification and Molecular Analysis of Pro-vitamin A Carotenoid Genes in Cassava (Manihot esculenta Crantz) Molecular Plant Breeding, Vol. 8 (4): $38-44$ http://mpb.biopublisher.ca.

[9] Underwood B. A, and Smitasii S (1999) Micronutrient malnutrition: Policies and Programs for control and their implications. Annual Review of Nutrition 19: 303.

[10] Combs G. F. (1998). The Vitamins Fundamental Aspects in Nutrition and Health. London.

[11] WHO (2009). Global prevalence of vitamin A deficiency in populations at risk 1995-2005. Geneva: World Health Organization.

[12] Pfeiffer, Wolfgang \& McClafferty, Bonnie. (2007).
HarvestPlus: Breeding Crops for Better Nutrition. Crop Science - CROP SCI. 47. 10.2135/cropsci2007.09.0020IPBS.

[13] Ekanayake I. J, Osiru D. S. O and Porto M. C. M (1997). Physiology of cassava. IITA Research Guide No. 55. $3^{\text {rd }}$ edition. IITA, Ibadan, Nigeria.

[14] Centro Internacional de Agricultura Tropical (CIAT). (2011). The Cassava Handbook. A Reference Manual based on the Asian Regional Cassava Training Course held in Thailand.

[15] Okechukwu, R. U. \& A. G. O. Dixon. (2009). Performance of improved cassava genotypes for early bulking, disease resistance, and culinary qualities in an inland valley ecosystem. Agronomy Journal 101: 1258-1265.

[16] Kamau, J., R. Melis, M. Laing, J. Derera, P. Shanahan, C. Eliud, \& K. Ngugi. (2011). Farmers'participatory selection for early bulking cassava genotypes in semi-arid Eastern Kenya. J. of Plant Breeding and Crop Sci 3: 44-52.

[17] Nweke F (2004). New challenges in the cassava transformation in Nigeria and Ghana.

[18] Ainsworth EA, Bush DR (2011) Carbohydrate export from the leaf: a highly regulated process and target to enhance photosynthesis and productivity. Plant Physiol 155: 64-69.

[19] Mohammad Siahpoosh R (2014). Sugar Partitioning and SinkSource Modifications in Plants. Journal of Rice Research, 3: 1

[20] Parry MA, Reynolds M, Salvucci ME, Raines C, Andralojc PJ, Zhu XG, Price GD, Condon AG, \& Furbank R. T. (2011). Raising yield potential of wheat. II. Increasing photosynthetic capacity and efficiency. Journal of Exp Bot. 62: 453-467.

[21] Reynolds M, Bonnett D, Chapman SC, Furbank RT, Manes Y, Mather DE, \& Parry M. A. (2011). Raising yield potential of wheat. I. Overview of a consortium approach and breeding strategies. Journal of Exp. Bot. 62: 439-452.

[22] Durand M, Mainson D, Porcheron B, Maurousset L, Lemoine R, \& Pourtau N (2018). Carbon source-sink relationship in Arabidopsis thaliana: the role of sucrose transporters. Planta 247: 587-611.

[23] Rosenthal D. M, Slattery R. A, Miller R. E, Grennan A. K, Cavagnaro T. R, Fauquet C. M, Gleadow R. M, Ort D. R. 2012. Cassava about- FACE: greater than expected yield stimulation of cassava (Manihot esculenta) by future $\mathrm{CO} 2$ levels. Global Change Biology 18: 2661-2675.

[24] Gleadow R. M, Evans J. R, McCaffery S, Cavagnaro T. R. 2009. Growth and nutritive value of cassava (Manihot esculenta Cranz.) are reduced when grown in elevated $\mathrm{CO} 2$. Plant Bio 11 (Suppl. 1): 76-82.

[25] Ihemere U, Arias-Garzon D, Lawrence S, Sayre R. 2006. Genetic modification of cassava for enhanced starch production. Plant Biotechnology Journal 4: 453-465.

[26] Yong-Ling Ruan, Craig Atkins (1999). Phloem Transport. Plant in Action, $1^{\text {st }}$ Ed.

[27] Alves, A. A. C. (2002). Cassava botany and physiology. In: R. J. Hillocks et al. (eds.), Cassava: Biology, production and utilization. CABI, Wallingford, UK. p. 67-89.

[28] Fukuda, W. M. G. C. L. Guevara, R. Kawuki, \& M. E. Ferguson (2010). Selected morphological and agronomic descriptors for the characterization of cassava, IITA, Ibadan. 
[29] Kawano, K (1980). Cassava. In: W. R. Fehr and H. H. Hadley. Eds. Hybridization of crop plants. ASA, CSSA, Madison, Wisconsin, USA. 225-233.

[30] Lemoine R, La Camera S, Atanassova R, Dedaldechamp F, Allario T, Pourtau N, Bonnemain JL, Laloi M, CoutosThevenot P, Maurousset L, Faucher M, Girousse C, Lemonnier P, Parrilla J, Durand M (2013) Source-to-sink transport of sugar and regulation by environmental factors. Front Plant Sci 4: 272

[31] Ramanujam T. (1985). Leaf density profile and efficiency in partitioning dry matter among high and low yielding cultivars of cassava (Manihot esculenta Crantz). Field Crops Res. 10: 291-303.

[32] Luo, X., \& Huang, Q. (2011). Relationships between leaf and stem soluble sugar content and tuberous root starch accumulation in cassava. Journal of Agricultural Science, 3, $64-72$.

[33] Zhang, Y., Ding, Z., Ma, F. et al. Transcriptional response to petiole heat girdling in cassava. Sci Rep 5, 8414 (2015) doi: 10.1038/srep08414.

[34] Thompson M, Gamagw D, Hinotsu N, Martin A and Seneweera S (2017). Effects of Elevated Carbondioxide on Photosynthesis and carbon partitioning: A perspective on Root Sugar Sensing and Hormonal Crosstalk. Front. Physiol., 8: 578 .

[35] Amanda P. De Souza \& Stephen P. Long (2017). Toward improving photosynthesis in cassava: Characterizing photosynthetic limitations in four current African cultivars. Food and Energy Security. published by John Wiley \& Sons Ltd. and the Association of Applied Biologists.

[36] Suja G, John K. S, Sreekumari J \& Srinivas T. (2009) Shortduration cassava genotypes for crop diversification in the humid tropics: growth dynamics, biomass, yield and quality. $J$ Sci Food Agric. 90: 188-98.

[37] Ober E. S \& Sharp R. E (2007). Regulation of root growth responses to water deficit. In: Jenks MA, Hasegawa P. M, Jain S. M, editors. Advances in molecular breeding toward drought and salt tolerant crops. New York: Springer; p. 33-53.

[38] Spollen W. G, LeNoble M. E, Samuels T. D, Bernstein N, Sharp R. E. (2000). ABA accumulation maintains primary root elongation at low water potentials by restricting ethylene production. Plant Physiol122: 967-76.

[39] Hershey, C., (2012). Cassava genetic improvement: theory and practice. FAO Publishing, Rome, Italy.

[40] Okogbenin E, Setter T. L, Ferguson M. E, Mutegi R, Ceballos H, Olasanmi B \& Fregene M. (2013) Phenotypic approaches to drought in cassava: review. Front Physiol. 4 (93): 1-15.

[41] Tumuhimbise, R., Shanahan P, Melis R. and Kawuki R. (2015). Genetic variation and association among factors influencing storage root bulking in cassava. Journal of Agricultural Science, 153: 1267-1280.

[42] Adu-Gyamfi R., Osei, C. and Anadumba, E. (2016). Yield and
Earliness in Bulking of Some Introduced Cassava Genotypes Under Moist Savanna. UDS International Journal of Development. Volume 3 No. 1.

[43] Okogbenin E, Marin J, Fregene M. (2008). QTL analysis for early yield in a pseudo $\mathrm{F} 2$ population of cassava. Afr. $J$. Biotech 7 (2): 31-138.

[44] El-Shakawy M. A. (2004). Cassava biology and physiology. Plt Mol Biol, 56 481-501.

[45] Hillocks R. J, Thresh J. M, and Anthony Bellotti (2002). Cassava: Biology, Production and Utilization. Wallingford, UK, CABI Pub.

[46] Silva, Rodrigo de Souza, Elisa Ferreira Moura, João Tomé de Farias Neto, and José Edson Sampaio (2016). Genetic parameters and agronomic evaluation of cassava genotypes. Pesq. agropec. bras., 51 (7): 834-841.

[47] Lessa, Lauro Saraiva, Carlos Alberto da Silva Ledo and Vanderlei da Silva Santos (2019). Effect of harvesting times on agronomic characteristics of industrial cassava genotypes. Revista Brasileira de Ciências Agrárias v. 14, n. 2, e5647, Recife, PE, UFRPE.

[48] Krieg, D. R. (1983). Photosynthetic activity during stress. Agr. Water Manage. 7: 249-263.

[49] Quisenberry, J. E., L. D. McDonald, \& B. L. McMichael. (1994). Response of photosynthetic rates to genotypic differences in sink-to-source ratios in upland cotton (Gossypium hirsutum L.). Environment Exp. Bot. 34: 245-252.

[50] Peressin, V. A, Montero, D. A, Lorenzi, J. O, Durigan, J. C, Pitelli, R. A and Perecini, D. (1998). Acumulo de Materia seca na Presenca e na ausencia de plantas infestantes no cultivar de Mandioca SRT 59- Branca de Santa Catarina, Bragantia 57: 135-148.

[51] Aina, O. O, Dixon, A. G. O. and Akinrinde, E. A. (2007) Effect of soil moisture stress on growth and yield of cassava in Nigeria. Pakistan Journal of Biological Sciences, 10: 30853090 .

[52] Ojulong, H, Labuschangne, M. T, Fregene, M and Herselman, L. A. (2008). Cassava clonal evaluation trial based on a new cassava breeding scheme. Euphytica, 160: 119-129, DOI: $10.1007 / \mathrm{s} 10681-007-9590-4$

[53] Lian TS, Cock JH. 1979. Branching habit as a yield determinant in cassava. Field Crops Research 2: 281-289.

[54] Rodrigo de Souza Silva, Elisa Ferreira Moura, João Tomé de Farias Neto and José Edson Sampaio, (2016). Genetic parameters and agronomic evaluation of cassava genotypes. Pesq. agropec. bras., Brasília, v. 51, n. 7, p. 834-841. DOI: 10.1590/S0100-204X2016000700006.

[55] Jailson L. Cruz, Daniel R. LeCain, Alfredo A. C. Alves, Mauricio Antonio Coelho Filho and Eugenio Ferreira Coelho (2018). Elevated CO2 reduces whole transpiration and substantially improves root production of cassava grown under water deficit, Archives of Agronomy and Soil Science. 64: 12, 1623-6234, DOI: 10.1080/03650340.2018.1446523. 